\title{
Correspondence
}

\section{Categorize probiotics to speed research}

As chairman of a panel convened in 2001-02 by the United Nations and the World Health Organization to establish guidelines for the use of probiotics, I am dismayed by recent regulatory changes in Europe and the United States.

These have led the European Food Safety Authority (EFSA) to override peer-reviewed studies in prestigious journals, and the US Food and Drug Administration (FDA) now requires an Investigational New Drug Application to be filed for probiotic foods or supplements that are intended to prevent or treat disease. The former has led to many negative ramifications for probiotic research and development in Europe, and the latter has halted research on probiotics at the US National Institutes of Health.

With the market for probiotics already exceeding US $\$ 30$ billion, and the Human Microbiome Project uncovering new candidate probiotic strains, I propose that the major agencies (at least EFSA and the FDA), together with international probiotic experts, create a simple categorization 'tree' system that would improve the adjudication process and be more informative for consumers. Every probiotic would need a set of minimal requirements, including strain designation and shelf life.

The lowest category would include yogurts that reduce adverse effects in lactoseintolerant individuals; other 'category 1' products would require only minimally documented studies in humans.

For the middle category, at least two randomized controlled studies would be needed to show how the probiotic works, with the results published in peerreviewed journals. This could include probiotic yogurts that, in addition to the lactose-digestion effect, reduce gut discomfort or increase intestinal transit time, as well as other probiotic products that counter adverse effects of antibiotics or restore microbial homeostasis to the vagina or mouth.

The third category would be reserved for products targeting vulnerable people such as infants and the elderly. It would include recombinant strains and species not previously used in foods and supplements - for example, bacteria producing neurochemicals that could improve cognitive function or memory. Strict adjudication would be required for products in category 3.

Gregor Reid Lawson Health Research Institute and University of Western Ontario, London, Ontario, Canada. gregor@uwo.ca

\section{Support home-grown plant collectors}

Plant collection continues today, but not always for conservation or taxonomy purposes (Nature 484, 436-438; 2012). The importation of ornamental plants has become a multibillion-dollar industry.

Unfortunately, some of the introduced plants destined for horticultural development can be a source of invasive alien weeds that affect human health, the economy and biodiversity. This risk can be offset by greater representation of native species in living collections and in horticulture.

We should be building national botanical knowledge and institutions to support a new generation of home-grown plant collectors in floristically rich regions. This will help to secure threatened flora and encourage botanic gardens to concentrate on the value and beauty of native species, rather than on showy introductions.

Little of the profit from the ornamental plant trade returns to the regions where the species were collected. Many countries now restrict the unregulated movement beyond their borders of native genetic resources such as seeds.

The institutions and industries that have benefited from the great foreign plant hunters of the past should not view these restrictions as an impediment, but as a reminder that they have an obligation to invest in the resident plant collectors of the future.

Philip E. Hulme The Bio-

Protection Research Centre,

Lincoln University, Canterbury,

New Zealand.

philip.hulme@lincoln.ac.nz

\section{Careless linking of Wallace and Darwin}

In his review of Darwin's Ghosts (Nature 485, 171-172; 2012), Andrew Berry misleadingly writes, "Even Alfred Russel Wallace, co-author of the paper that first unveiled evolution by natural selection, has mostly disappeared from view", adding, "The outcomes [of an intervention by colleagues] were a paper co-published by Darwin and Wallace in the Journal of the Linnean Society in July 1858, and Origin in November the next year."

The terms 'co-author' and 'co-publish' wrongly imply that Darwin and Wallace were joint authors of a single paper and joint publishers of the (incorrectly titled) journal.

The facts were well stated by geologist Charles Lyell and botanist Joseph Hooker, who on 1 July 1858 presented to the Linnean Society an essay by Wallace, together with two contributions from Darwin (extracts from a manuscript on species and an abstract of a letter to US botanist Asa Gray). Lyell and Hooker wrote: "The accompanying papers [...] all relate to the same subject, viz. the Laws which affect the Production of Varieties, Races, and Species, [and] contain the results of the investigations of two indefatigable naturalists, Mr. Charles Darwin and Mr. Alfred Wallace." These three 'papers' were first printed in 1858 (J. Proc. Linn. Soc. $3,45-62 ; 1858)$, and later in volume form in 1859 .

K. Razi Naqvi Norwegian University of Science and Technology, Trondheim, Norway. razi.naqvi@ntnu.no

\section{Monitoring fungal infections in fish}

Freshwater fish should be added to the list of species that are threatened by emerging fungal diseases (M. C. Fisher et al. Nature 484, 186-194; 2012). Government agencies need to adapt their fish-monitoring programmes to establish the extent of the damage these pathogens are causing.

Freshwater fish are important for millions of people in eastern Asia, for example, but fungal diseases are spreading fast there, helped by invasive species that carry fungal pathogens (R.E. Gozlan et al. Fish Fish. 11, 315-340; 2010).

It is essential to convince cash-strapped government agencies that experimental work can give insight into realworld epidemiology, and that a major impact of disease on fish populations could go unnoticed using current monitoring systems, which don't work for fish living in muddy waters.

Rodolphe Gozlan Bournemouth University, Poole, Dorset, UK. rgozlan@bournemouth.ac.uk

CONTRIBUTIONS

Correspondence may be sent to correspondence@ nature.com after consulting the guidelines at go.nature. com/cmchno. Alternatively, readers may comment online on anything published in Nature at: www.nature.com/nature. 